CLINICAL STUDY

\title{
High urinary ACE2 concentrations are associated with severity of glucose intolerance and microalbuminuria
}

\author{
Se Eun Park, Won Jun Kim, Sung Woo Park, Ji Woo Park ${ }^{1}$, Namseok Lee ${ }^{1}$, Cheol-Young Park* and \\ Byung-Soo Youn ${ }^{1}$ \\ Department of Endocrinology and Metabolism, Kangbuk Samsung Hospital, Sungkyunkwan University School of Medicine, Seoul, Republic of Korea \\ and ${ }^{1}$ AdipoGen, Inc., Room 401, MeetYouAll Tower Annex B, Incheon Technopark, 7-50 Songdo-dong, Yeonsu-gu, Incheon, 406-840 Republic of Korea \\ (Correspondence should be addressed to C-Y Park; Email: cydoctor@chol.com; or to B-S Youn; Email: bsyoun@adipogen.com)
}

*(C-Y Park is now at Division of Endocrinology and Metabolism, Department of Internal Medicine, Kangbuk Samsung Hospital, Sungkyunkwan University School of Medicine, No. 108 Pyung-Dong, Jongro-Ku, Seoul 110-746, Republic of Korea)

\begin{abstract}
Objective: Angiotensin-converting enzyme 2 (ACE2) plays an important role in glucose metabolism and renal function. However, the relationship between ACE2 and hyperglycemia or microalbuminuria has not been established in humans. We investigated whether urinary ACE2 levels are associated with abnormal glucose homeostasis and urinary albumin excretion.

Methods: We developed an ELISA for quantifying ACE2 in urine. The ELISA was used to measure urinary ACE2 levels in 621 subjects with: normal glucose tolerance (NGT; $n=77$ ); impaired fasting glucose (IFG) or impaired glucose tolerance (IGT) $(n=132)$; and type 2 diabetes mellitus (T2DM, $n=412$ ). Insulin resistance was assessed by homeostasis model assessment for insulin resistance (HOMA-IR) index and urinary albumin excretion by urine albumin-to-creatinine ratio (ACR). Other biochemical and anthropometric parameters were measured.

Results: Urinary ACE2 levels were significantly higher in insulin-resistant subjects with IFG, IGT, and T2DM than in the NGT group $(P<0.001)$. Urinary ACE2 concentrations appeared to correlate with HOMA-IR, fasting blood glucose, triglyceride, high-sensitivity C-reactive protein, serum creatinine, urinary ACR, and systolic blood pressure (all $P<0.05$ ). After adjustment for impaired renal function and other metabolic parameters, urinary ACE2 concentration was still associated with a higher risk for T2DM (OR 1.80, 95\% CI 1.05-3.08, $P=0.02$ ). In addition, urinary ACE2 levels were highly predictive of microalbuminuria after adjusting for clinical risk factors (OR 2.68, 95\% CI 1.55-4.64, P<0.001). Conclusion: Our data suggest that the urinary ACE2 level is closely associated with T2DM and is an independent risk factor for microalbuminuria.
\end{abstract}

European Journal of Endocrinology 168 203-210

\section{Introduction}

The mechanisms involved in the development of type 2 diabetes mellitus (T2DM) and its complications are complex, with a long list of potential derangements in different pathways $(1,2)$. Both clinical trials and animal models of T2DM have shown that the renin-angiotensin system (RAS) contributes to the development of T2DM and its complications (3). Of clinical relevance, blockade of the RAS prevents new-onset T2DM and reduces the risk of T2DM and its complications $(4,5)$.

Angiotensin-converting enzyme (ACE) has long been recognized as the key enzyme within the RAS, as it is involved in cleaving angiotensin (Ang) I to form Ang II, which is the main active peptide within the system. ACE2, a first homolog of ACE, is a monocarboxypeptidase that preferentially removes carboxy-terminal amino acids from various substrates, including Ang II, Ang I, and apelin $(6,7,8,9)$. ACE2 cleaves Ang II to form Ang-(1-7) (10). Alterations in glucose tolerance and reduced first-phase insulin secretion have been described in ACE2-deficient mice, suggesting a potential role of ACE2 in the development of T2DM (11).

Microalbuminuria is an early marker of diabetic nephropathy and an independent risk factor for cardiovascular disease $(12,13)$. Previous data have demonstrated that microalbuminuria is associated with insulin resistance in type 2 diabetic patients as well as in nondiabetic individuals (14). Thus, the early identification and treatment of patients at increased risk for microalbuminuria may be important for preventing renal and cardiovascular diseases associated with T2DM. A number of studies have reported a relationship between RAS and proteinuria $(15,16)$. In the kidney, ACE2 is localized in the proximal tubules and glomerulus (17). Previously, it was reported that renal expression of ACE2 is downregulated in T2DM $(18,19)$, whereas others showed that ACE2 expression and ACE2 
activity were increased in animal models of diabetes (20, 21). Additionally, a positive relationship between urinary mRNA expression of ACE2 and the degree of proteinuria in human type 2 diabetic nephropathy has been reportedly found (22). Soluble ACE2, as well as ACE, can be detected in urine (23). A recent study identified a significant difference in urinary ACE2 levels between subjects with chronic kidney disease (CKD) and healthy subjects (24). Accordingly, ACE2 is important as a potential participant in the development of both T2DM and nephropathy (25). However, a relationship between urinary concentrations of ACE2 and glycemia or microalbuminuria has not been established.

In this study, we investigated the relationships of urinary ACE2 concentrations with glucose metabolism and urinary albumin excretion status. To further evaluate the role of urinary ACE2, we assessed the relationships between urinary ACE2 levels and various metabolic parameters.

\section{Materials and methods}

\section{Participants}

Between September 2007 and September 2008, subjects aged 21-80 years with a history of hyperglycemia (fasting plasma glucose $\geq 5.5 \mathrm{mmol} / \mathrm{ml}$ ) or T2DM were enrolled in the Seoul Metro-City Diabetes Prevention Program (SMC-DPP) (26). The subjects were recruited from five public health centers. After exclusion of subjects taking antiobesity medications or corticosteroids and those with histories of diabetic ketoacidosis, symptomatic heart failure, and renal or hepatic dysfunction, assignment to one of the groups was performed using a $75 \mathrm{~g}$ oral glucose tolerance test according to the diagnostic criteria of the American Diabetes Association (27). We recruited 621 subjects with: normal glucose tolerance (NGT); impaired fasting glucose (IFG), impaired glucose tolerance (IGT), or IFG + IGT; or T2DM who had adequate, stable renal function (serum creatinine $(\mathrm{Cr})<2.0 \mathrm{mg} / \mathrm{dl}$ ). All participants provided written informed consent. This study was approved by the Institutional Review Board at Kangbuk Samsung Hospital.

\section{Anthropometric and laboratory measurements}

BMI $\left(\mathrm{kg} / \mathrm{m}^{2}\right)$ was calculated as body weight in kilograms divided by height in meters squared. Blood pressures were measured using a sphygmomanometer (Welch Allyn, Inc., Vital Signs Monitor 300 series, Skaneateles Falls, NY, USA) between 0800 and $1000 \mathrm{~h}$ after at least $5 \mathrm{~min}$ of rest, according to the Hypertension Detection and Follow-up Program protocol (28). Trained nurses measured seated blood pressure. When the SBP or DBP exceeded 140 or
$90 \mathrm{mmHg}$, it was remeasured after a 5-min rest, and the results averaged.

Blood samples were collected following an overnight fast. The subjects also provided the first morning specimen of urine. Aliquots of both plasma and urine were stored at $-80{ }^{\circ} \mathrm{C}$ until assayed. Height, weight, and waist circumferences were measured. Plasma glucose concentrations were determined using a Beckman glucose analyzer II (Beckman Instruments, Fullerton, CA, USA). HbA1c was measured using HPLC (Variant II, Bio-Rad Laboratories). The assay coefficient of variability $(\mathrm{CV})$ for glucose was $<1.5$ and $<3.0 \%$ for $\mathrm{HbA1c}$. Serum insulin levels were measured using an immunoradiometric assay (Biosource, Nivells, Belgium) following the manufacturer's recommendations. Plasma lipids, including total cholesterol, triglyceride, HDL-C, and ILDL-C, were measured by enzymatic colorimetric assay (Siemens, Tarrytown, NY, USA). Serum high-sensitivity C-reactive protein (hsCRP) levels were measured by nephelometric assay using a BNII nephelometer (Dade Behring, Deerfield, IL, USA), and the detection limit was $0.175 \mathrm{mg} / \mathrm{l}$ with a sample dilution of $1: 20$. Homeostasis model assessment for insulin resistance (HOMA-IR) was calculated as described previously (29). Serum creatinine was measured using the timedend point method (Unicel DxC 800, Beckman and Coulter, Krefeld, Germany).

Urinary albumin-to-creatinine ratio (ACR) was calculated using consecutive morning and daytime urine specimens by an immunonephelometric method using the DCA 2000 albumin/creatinine ratio urinanalyzer (Bayer Corp.). The intra-assay and interassay CV were reported as being within the range 2 and $8 \%$ for ACR. Microalbuminuria was defined as an ACR of $30-300 \mu \mathrm{g} / \mathrm{mg}$ creatinine. Glomerular filtration rate was estimated by the Modification of Diet in Renal Disease (MDRD) Study Group formula (estimated glomerular filtration rate, eGFR). In accordance with the National Kidney Foundation Disease Outcomes Quality Initiative classification system, CKD was defined on the basis of eGFR and categorized into three groups defined by the cutoff points. Therefore, subjects in the stage $1-2$ CKD group had eGFRs $\geq 60 \mathrm{ml} / \mathrm{min}$ per $1.73 \mathrm{~m}^{2}$, the stage $3 \mathrm{CKD}$ group had eGFRs $<60$ to $\geq 30 \mathrm{ml} / \mathrm{min}$ per $1.73 \mathrm{~m}^{2}$, and the stage 4-5 CKD group had eGFRs $<30 \mathrm{ml} / \mathrm{min}$ per $1.73 \mathrm{~m}^{2}(30)$. Subjects with an eGFR $\geq 90 \mathrm{ml} / \mathrm{min}$ per $1.73 \mathrm{~m}^{2}$ without proteinuria or history of kidney disease were placed in stage 0 .

\section{Development of human ACE2 ELISA and measurement of urinary ACE2 concentrations}

A cDNA sequence encoding the original signal peptide sequence and the mature peptide of human ACE2, excluding the transmembrane domain, and a short stretch of cytoplasmic tail, was amplified with the 
following primer set: i) forward primer $5^{\prime}$-cctagctagcgggacgatgtcaagctcttc- $3^{\prime}$ and ii) reverse primer $5^{\prime}$-gccgctcgaggggctggttaggaggtccaag- $3^{\prime}$. The sequence was then digested with NheI and XhoI and cloned into both pAGCF (AdipoGen, Incheon, Korea). A FLAG tag was incorporated at the $\mathrm{COOH}$ terminus of the human ACE2 peptide. The tagged protein was expressed in a human embryonic kidney cell line, HEK-293, and purified from conditioned media through an antiFLAG sepharose column. Polyclonal antibody (PAb) was then produced by immunization with recombinant FLAG-tagged human ACE2 according to a general protocol. Immunoglobulin fractions were prepared from serum and then biotinylated. FLAG-tagged ACE2 was used as the ELISA standard at a variety of dilutions. A sandwich ELISA format was designed using a pair of $\mathrm{PAb}$ and biotinylated PAb. One hundred microliters of human urine in 1:2 dilutions were applied to each well, which had been coated with $5 \mu \mathrm{g} / \mathrm{ml}$ of a human ACE2specific PAb and incubated at $37^{\circ} \mathrm{C}$ for $1 \mathrm{~h}$, followed by washing three times with PBS with $0.05 \%$ Tween 20 (PBST). One hundred microliters of the biotinylated PAb at $5 \mathrm{mg} / \mathrm{ml}$ were added per well. The secondary antibody reaction was performed at $37^{\circ} \mathrm{C}$ for $1 \mathrm{~h}$, followed by washing three times with PBST. A colorimetric reaction was conducted for 20 min using HRP-conjugated streptavidin (Zymed, South San Francisco, CA, USA) diluted 1:1000 in PBS and 2,2'-azinobis(2-ethylbenzothiazoline-6-sulfonic acid) (Pierce, Rockford, IL, USA) as the substrate. The optical density was measured at $450 \mathrm{~nm}$; its sensitivity was $293 \mathrm{pg} / \mathrm{ml}$. While the degree of precision of the ELISA system in terms of the intra-assay CV was between 6.1 and $9.9 \%$ (Supplementary Table 1, see section on supplementary data given at the end of this article), the inter-assay CV were between 5.4 and 10.8\% (Supplementary Table 2). Spike recovery (Supplementary Table 3) and linearity (Supplementary Table 4) were in the ranges of 90-100 and $89-107 \%$ respectively. Specificity was determined such that it would not cross-react with human ACE1, mouse ACE2, human adiponectin, human leptin, human resistin, human visfatin, human clusterin, human retinal binding protein 4 , human resistin-like molecule- $\alpha$ (RELM- $\alpha$ ), human IL23, human angiopoietin 1 , human angiopoietin 2 , human fatty acid binding protein 4, human angiopoietin-like protein 6 (ANGPTL6), human plasminogen activator inhibitor-1 (PAI-1), human vaspin, or mouse RELM- $\beta$ (Supplementary Table 5).

\section{Statistical analysis}

Analyses were performed using SPSS for Windows software (version 17.0; SPSS). We used ANOVA, Wilcoxon rank sum tests, and Kruskal-Wallis tests for comparisons of continuous variables and $\chi^{2}$ tests for comparison of categorical variables. Bivariate correlation analyses between urinary ACE2 and the metabolic parameters were performed using Pearson's correlation analysis. Multivariate logistic regression analysis was performed to investigate associations between T2DM or microalbuminuria with urinary ACE2 levels. $P$ values $<0.05$ were considered significant.

\section{Results}

Baseline characteristics of the study participants are shown in Table 1 . The mean age ( \pm s.D.) was 59.8 ( \pm 12.8 ) years and $51.4 \%$ of the participants were male. The duration of diabetes in T2DM subjects was 3.1 \pm 5.2 years. With increasing impairment of glucose metabolism, we detected expected group differences in age, waist circumference, fasting blood glucose, $\mathrm{HbAlc}$, total cholesterol, triglyceride, HDL-C, fasting insulin, insulin sensitivity (HOMA-IR), hsCRP, and blood pressure values. Subjects with T2DM exhibited evidence of impaired renal function, as indicated by higher serum $\mathrm{Cr}$, lower eGFR, and urinary ACR values. There were significant differences in urinary ACE2 concentrations between subjects with NGT, IFG, or IGT and T2DM (all $P<0.05$ ). Among the subjects, 41.7, 40.4, 15.5, and $20.4 \%$ had stage $0,1,2$, and 3 for CKD respectively. Urinary ACE2 levels were increased according to the stage of CKD. The median (interquartile range) for urinary ACE2 was 2.19 (1.30-4.33) for CKD stage 0, 2.58 (1.52-4.14) for CKD stage 1, 3.78 (2.12-6.55) for CKD stage 2 , and $6.59(3.54,9.41)$ for CKD stage 3 respectively $(P<0.01)$. After adjusting for age, sex, and BMI, urinary ACE2 concentrations were correlated with fasting blood glucose, triglyceride, HOMA-IR, hsCRP, systolic blood pressure, serum $\mathrm{Cr}$, and urinary ACR levels (Table 2, all $P<0.05$ ).

Urinary ACE2 levels were grouped into tertiles to simplify interpretation of the results of subsequent analyses. With respect to metabolic parameters, subjects in the higher ACE2 tertiles exhibited higher values for age, fasting blood glucose, HbAlc, triglyceride, HOMA-IR, hsCRP, systolic blood pressure, serum $\mathrm{Cr}$, and urinary ACR (all $P<0.05$ ) than those in the lower tertile (Table 3).

As shown in Table 4, increased urinary ACE2 concentrations were associated with an increased risk of hyperglycemia. Subjects with a higher level of urinary ACE2 had a higher risk of T2DM after adjusting for age, sex, BMI, and several metabolic parameters (OR 1.80, 95\% CI 1.05-3.08, $P=0.033)$. The corresponding OR for both impaired glucose regulation (IFG or IGT) and T2DM was 1.88 (95\% CI $1.01-3.47, P=0.045)$.

Multivariate linear regression analysis also showed that urinary ACE2 concentrations were associated with a high risk of microalbuminuria (OR 2.68, 95\% CI 1.55-4.64, $P<0.001)$ even after controlling for clinical risk factors (Table 5). 
Table 1 Baseline characteristics of the study sample. Data are summarized as mean \pm s.D., median (interquartile range) for non-normal distribution, or $n(\%)$. HbA1c is expressed as \% and $\mathrm{mmol} / \mathrm{l}$.

\begin{tabular}{|c|c|c|c|c|}
\hline & NGT $(n=77)$ & IFG or IGT $(n=132)$ & T2DM $(n=412)$ & $P$ value \\
\hline Age (years) & $41.3 \pm 10.2$ & $58.8 \pm 12.4$ & $63.5 \pm 10.1$ & $<0.001$ \\
\hline $\operatorname{Sex}(M / F)$ & $60 / 1 \overline{7}$ & $60 / 7 \overline{2}$ & $199 / 213$ & $<0.001$ \\
\hline $\mathrm{BMI}\left(\mathrm{kg} / \mathrm{m}^{2}\right)$ & $22.7 \pm 3.3$ & $24.6 \pm 3.3$ & $25.5 \pm 11.4$ & 0.056 \\
\hline Waist circumference $(\mathrm{cm})$ & $78.4 \pm 9.9$ & $84.4 \pm 11.5$ & $88.1 \pm 15.7$ & $<0.001$ \\
\hline Fasting blood glucose (mmol/l) & $5.30 \pm 0.60$ & $6.31 \pm 0.59$ & $8.39 \pm 2.13$ & $<0.001$ \\
\hline $\mathrm{HbA} 1 \mathrm{c}(\%, \mathrm{mmol} / \mathrm{mol})$ & $\begin{array}{l}5.39 \pm 0.12 \\
(35.38 \pm 4.56)\end{array}$ & $\begin{array}{l}5.79 \pm 0.36 \\
(39.74 \pm 3.91)\end{array}$ & $\begin{array}{l}7.35 \pm 1.33 \\
(56.80 \pm 14.49)\end{array}$ & $<0.001$ \\
\hline Total cholesterol $(\mathrm{mmol} / \mathrm{l})$ & $4.66+0.79$ & $0.51+0.94$ & $4.87+0.98$ & 0.007 \\
\hline Triglycerides $(\mathrm{mmol} / \mathrm{l})$ & $0.90(0.55-1.48)$ & $1.36(0.98-1.81)$ & $1.52(1.08-2.22)$ & $<0.001$ \\
\hline $\mathrm{HDL}-\mathrm{C}(\mathrm{mmol} / \mathrm{l})$ & $1.38 \pm 0.31$ & $1.37 \pm 0.32$ & $1.28 \pm 0.34$ & 0.005 \\
\hline LDL-C (mmol/l) & $2.84 \pm 0.78$ & $2.90 \pm 0.83$ & $2.71 \pm 0.85$ & 0.064 \\
\hline Fasting insulin (pmol/l) & $39.6(25.2-53.5)$ & $63.3(51.1-82.0)$ & $72.9(57.2-99.9)$ & $<0.001$ \\
\hline HOMA-IR (arbitrary unit) & $2.07(1.53-2.85)$ & $2.52(2.02-3.48)$ & $3.90(2.92-5.30)$ & $<0.001$ \\
\hline hsCRP (mg/l) & $0.06(0.04-0.10)$ & $0.06(0.03-0.13)$ & $0.09(0.04-0.22)$ & $<0.001$ \\
\hline Taking antihypertensive drugs, $n(\%)$ & $2(2.6)$ & $49(37.1)$ & $245(59.5)$ & $<0.001$ \\
\hline Systolic blood pressure $(\mathrm{mmHg})$ & $114.1 \pm 10.8$ & $128.9 \pm 9.4$ & $133.6 \pm 18.7$ & $<0.001$ \\
\hline Diastolic blood pressure $(\mathrm{mmHg})$ & $70.9 \pm 8.3$ & $83.7 \pm 2.8$ & $83.4 \pm 12.0$ & $<0.001$ \\
\hline Urinary ACR (mg/g) & $6.0(\overline{5} .0-10.8)$ & $11.5(6.9-32.0)$ & $23.3(9.8-63.1)$ & $<0.001$ \\
\hline Serum creatinine concentration $(\mathrm{mg} / \mathrm{dl})$ & $0.85 \pm 0.19$ & $0.74 \pm 0.20$ & $0.78 \pm 0.20$ & 0.001 \\
\hline eGFR $\left(\mathrm{ml} / \mathrm{min}\right.$ per $\left.1.73 \mathrm{~m}^{2}\right)$ & $100.0 \pm 22.4$ & $92.5 \pm 29.5$ & $82.9 \pm 26.9$ & $<0.001$ \\
\hline Urinary ACE2 (ng/ml) & $2.18(1.38-3.70)$ & $2.44(1.33-3.96)$ & $3.00(1.61-4.97)$ & 0.002 \\
\hline Current smoking (\%) & $2(2.6)$ & $13(9.8)$ & $59(14.3)$ & 0.010 \\
\hline Current alcohol intake (\%) & $5(6.5)$ & $52(39.4)$ & $11.9(28.9)$ & $<0.001$ \\
\hline
\end{tabular}

NGT, normal glucose tolerance; IFG, impaired fasting glucose; IGT, impaired glucose tolerance; T2DM, type 2 diabetes mellitus; HOMA-IR, homeostasis model assessment of insulin resistance; hsCRP, high-sensitivity C-reactive protein; ACR, albumin-to-creatinine ratio; eGFR, estimated glomerular filtration rate.

\section{Discussion}

This study demonstrated that urinary ACE2 levels appear to be elevated in subjects with T2DM and are associated with various metabolic parameters. We also found that urinary ACE2 levels are associated with a higher risk of microalbuminuria, independent of various confounding factors. The results of this study imply that urinary ACE2 concentration may be a valuable marker for both glucose intolerance and microalbuminuria.

Previous studies suggest that ACE2 may play a pivotal role in T2DM. Ang II can delay insulin secretion and reduce blood flow in the islets of Langerhans in rodents. Consistent with this effect of Ang II, blockade of the RAS with either ACE inhibitors or Ang II receptor blockers increases islet blood flow (31). These findings are particularly relevant given clinical evidence that RAS blockade may be associated with reduced incidence of new-onset T2DM (32). ACE2 is elevated in T2DM and may be involved in a compensatory mechanism opposing the ACE/Ang II/AT1 receptor axis, leading to improved glucose tolerance in animal models (3). We therefore hypothesized that urinary ACE2 concentrations are closely related to glucose intolerance and metabolic parameters.

We developed an ELISA for the measurement of human urinary ACE2 concentrations. Takahashi et al. (33) employed an immunoprecipitation technology for
Table 2 Correlations between urinary ACE2 and various metabolic parameters.

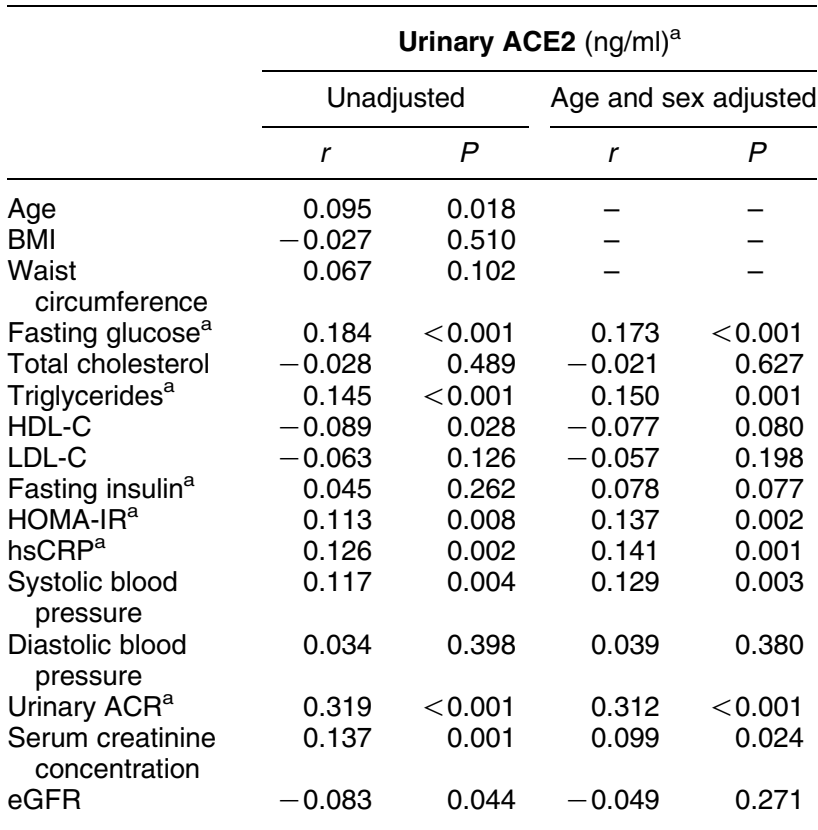

HOMA-IR, homeostasis model assessment of insulin resistance; hsCRP, high-sensitivity C-reactive protein; ACR, albumin-to-creatinine ratio; eGFR, estimated glomerular filtration rate.

a.37wLogarithmic transformation was performed because of a skewed distribution. 
Table 3 Metabolic risk factors according to urinary ACE2 tertile. Data are summarized as mean \pm s.D., median (interquartile range) for non-normal distribution.

\begin{tabular}{|c|c|c|c|c|}
\hline Characteristics & $\begin{array}{l}\mathrm{I}(n=207) \\
\leq 1.92 \mathrm{ng} / \mathrm{ml}\end{array}$ & $\begin{array}{l}\text { II }(n=209) \\
1.93-3.76 \mathrm{ng} / \mathrm{ml}\end{array}$ & $\begin{array}{l}\text { III }(n=205) \\
\geq 3.77 \mathrm{ng} / \mathrm{ml}\end{array}$ & $P$ value \\
\hline Age (years) & $58.9 \pm 12.3$ & $58.7 \pm 13.1$ & $61.7 \pm 12.9$ & 0.030 \\
\hline $\operatorname{Sex}(M / F)$ & $92 / 115$ & $112 / 97$ & $115 / 90$ & 0.045 \\
\hline BMI $\left(\mathrm{kg} / \mathrm{m}^{2}\right)$ & $25.7 \pm 15.7$ & $24.6 \pm 3.3$ & $24.6 \pm 3.4$ & 0.372 \\
\hline Waist circumference $(\mathrm{cm})$ & $83.5 \pm 16.3$ & $85.4 \pm 12.4$ & $85.4 \pm 14.3$ & 0.330 \\
\hline Fasting blood glucose (mmol/l) & $7.28 \pm 1.73$ & $7.39 \pm 2.02$ & $8.02 \pm 2.51$ & 0.001 \\
\hline $\mathrm{HbA} 1 \mathrm{c}(\%)$ & $6.65 \pm 1.24$ & $6.77 \pm 1.34$ & $7.17 \pm 1.50$ & $<0.001$ \\
\hline Total cholesterol (mmol/l) & $4.99 \pm 0.93$ & $4.86 \pm 0.94$ & $4.83 \pm 1.01$ & 0.212 \\
\hline Triglycerides $(\mathrm{mmol} / \mathrm{l})$ & $1.29(0.94-1.79)$ & $1.47(0.96-2.24)$ & $1.46(1.08-2.16)$ & 0.008 \\
\hline $\mathrm{HDL}-\mathrm{C}(\mathrm{mmol} / \mathrm{l})$ & $1.35 \pm 0.32$ & $1.30 \pm 0.33$ & $1.28 \pm 0.34$ & 0.084 \\
\hline LDL-C (mmol/l) & $2.85 \pm 0.82$ & $2.78 \pm 0.86$ & $2.67 \pm 0.85$ & 0.129 \\
\hline Fasting insulin (pmol/l) & $66.4(50.3-64.7)$ & $67.9(50.9-94.6)$ & $70.0(52.2-88.3)$ & 0.432 \\
\hline HOMA-IR (arbitrary unit) & $3.26(2.41-4.46)$ & $3.64(2.45-5.08)$ & $3.67(2.72-4.72)$ & 0.048 \\
\hline hsCRP (mg/l) & $0.07(0.03-0.17)$ & $0.07(0.03-0.17)$ & $0.10(0.05-0.21)$ & 0.003 \\
\hline Taking antihypertensive drugs, $n(\%)$ & $83(40.1)$ & $95(45.5)$ & $118(57.6)$ & 0.001 \\
\hline ACE/ARB (\%) & $30(14.5)$ & 34 (16.3) & $38(18.5)$ & 0.540 \\
\hline Systolic blood pressure (mmHg) & $129.0 \pm 18.8$ & $128.3 \pm 18.2$ & $133.3 \pm 20.0$ & 0.017 \\
\hline Diastolic blood pressure $(\mathrm{mmHg})$ & $82.2 \pm 12.3$ & $81.1 \pm 2.6$ & $82.6 \pm 12.6$ & 0.441 \\
\hline Urinary ACR $(\mathrm{mg} / \mathrm{g})$ & $11.3(6.6-31.5)$ & $14.2(7.1-43.8)$ & $24.8(9.0-97.1)$ & $<0.001$ \\
\hline Serum creatinine concentration $(\mathrm{mg} / \mathrm{dl})$ & $0.75 \pm 0.19$ & $0.78 \pm 0.19$ & $0.82 \pm 0.23$ & 0.005 \\
\hline eGFR $\left(\mathrm{ml} / \mathrm{min}\right.$ per $\left.1.73 \mathrm{~m}^{2}\right)$ & $88.8 \pm 26.6$ & $88.3 \pm 26.5$ & $84.1 \pm 29.8$ & 0.179 \\
\hline
\end{tabular}

HOMA-IR, homeostasis model assessment of insulin resistance; hsCRP, high-sensitivity C-reactive protein; ACEi/ARB angiotensin-converting enzyme inhibitor/angiotensin II receptor blocker; ACR, albumin-to-creatinine ratio; eGFR, estimated glomerular filtration rate.

detection of serum ACE2 after removing nucleic acids with the use of an antihuman ACE2 antibody. In parallel with the use of our urinary ACE2 immunoassay, Mizuiri et al. (24) concentrated human sera after removing serum IgG and was able to detect serum ACE2. Regarding the measurement of human ACE2, Dilauro et al. (34) utilized a fluorescence dye-based enzymatic assay that was distinguished from ACE. Recently, Xiao et al. (35) described the presence of urinary ACE2 using an effective western blot analysis in comparison with the current immunoassay and mRNA expression levels, in human urine samples and tissues of a group of diabetic patients with renal transplant. This study showed that both the current ELISA and the western blot were the far more reliable means for measuring the presence of urinary ACE2 than the enzymatic activities in terms of statistics, suggesting that the current ELISA can be more widely and safely applied to measurement of urinary ACE2.
In the current study, urinary ACE2 concentrations were elevated in patients with glucose intolerance and positively related to fasting blood glucose, suggesting that elevated urinary ACE2 might reflect the severity of glucose intolerance. This is the first study to demonstrate that urinary ACE2 levels might reflect the severity of glucose intolerance. We also found that urinary ACE2 concentrations are correlated with metabolic parameters and the insulin resistance index assessed by HOMA-IR. Recently, Ang-(1-7) binding to the Mas receptor was shown to inhibit Ang II responses (36). Santos et al. (37) reported that Mas - / - mice exhibit impaired insulin sensitivity and glucose tolerance, reduced adipose glucose uptake, and impaired glucose transporter 4, which implies that the ACE2/Ang-(1-7)/ Mas receptor axis is closely related to the development of insulin resistance. Although the precise mechanisms explaining the role of ACE2 in glucose metabolism are not understood, the link between ACE2 and insulin

Table 4 Risk of type 2 diabetes mellitus with an increase in log(urinary ACE2 ( $\mathrm{ng} / \mathrm{ml}))$. Values are ORs $(95 \% \mathrm{Cl})$.

\begin{tabular}{|c|c|c|c|}
\hline Model & Adjustment & Type 2 diabetes mellitus & $P$ value \\
\hline Model 1 & Unadjusted & $1.47(1.37,3.40)$ & 0.002 \\
\hline Model 2 & $\begin{array}{l}\text { Adjusted for age, sex, current smoking, and } \\
\text { current alcohol intake, based on Model } 1\end{array}$ & $1.92(1.16,3.19)$ & 0.011 \\
\hline Model 3 & $\begin{array}{l}\text { Further adjusted for BMI, total cholesterol, } \\
\text { insulin, and hsCRP, based on Model } 2\end{array}$ & $1.85(1.08,3.16)$ & 0.024 \\
\hline Model 4 & $\begin{array}{l}\text { Further adjusted for ACEi/ARB use, based } \\
\text { on Model } 3\end{array}$ & $1.80(1.05,3.08)$ & 0.033 \\
\hline
\end{tabular}

hsCRP, high-sensitivity C-reactive protein; ACEi/ARB, angiotensin-converting enzyme inhibitor/angiotensin II receptor blocker. 
Table 5 Risk of microalbuminuria associated with an increase in log(urinary ACE2 (ng/ml)). Values are ORs (95\%).

\begin{tabular}{llll}
\hline Model & Adjustment & $\begin{array}{c}\text { Microalbuminuria } \\
(n=208)\end{array}$ & $\boldsymbol{P}$ value \\
\hline Model 1 & Unadjusted & $3.35(2.06,5.45)$ & $<0.001$ \\
Model 2 & Adjusted for age, sex, BMl, current smoking, & $3.15(1.90,5.21)$ & $<0.001$ \\
Model 3 & $\begin{array}{l}\text { Further adjusted for total cholesterol, insulin, } \\
\text { and hsCRP, based on Model 2 }\end{array}$ & $2.74(1.60,4.67)$ & $<0.001$ \\
Model 4 & Further adjusted for systolic blood pressure, & $2.68(1.55,4.64)$ & $<0.001$ \\
& ACEi/ARB use, and eGFR, based on Model 3 & & \\
\hline
\end{tabular}

hsCRP, high-sensitivity C-reactive protein; ACEi/ARB, angiotensin-converting enzyme inhibitor/angiotensin II receptor blocker; eGFR, estimated glomerular filtration rate.

resistance and other metabolic parameters could provide one explanation with respect to glucose metabolism.

Additionally, we showed that ACE2 appears to be positively associated with inflammatory cytokines reflected by hsCRP concentrations. Ang II is well known for its pro-inflammatory action (38), while several studies have demonstrated the ability of ACE2 to inhibit these effects in a disease state (39). Increased inflammation contributes to the development of islet dysfunction and loss of islet morphology (40), which is one potential cause of pancreatic $\beta$-cell failure (41). It is possible that ACE2 might have a causal role in systemic inflammation related to the development of T2DM. However, it appears that the relationship between urinary ACE2 and T2DM is consistent, independent of the presence of an inflammatory marker. The mechanism remains unclear, but these results suggest that urinary ACE2 might play a direct role in the severity of glucose intolerance through other mechanisms that do not fully overlap with those of the inflammatory pathways. Further studies are needed to determine whether ACE2 plays a causal role in the regulation of glucose metabolism in humans.

Urinary ACE2 levels are associated with microalbuminuria in our study. Additionally, urinary ACE2 levels are increased according to the stage of CKD. Although this study cannot affirm the cellular origin of urinary ACE2 protein, it could originate at least partly from plasma via glomerular filtration, or it could be derived via excretion from renal cells. A recent study reported increased urinary levels of ACE2 in CKD and diabetic nephropathy, whereas there were no differences in serum ACE2 protein expression (24). However, patients with CKD in their study had significant albuminuria, suggesting that ACE2 may have leaked into the urine across the glomerular barrier. ACE2 is shed at its carboxy-terminus from the plasma membrane in cultured human embryonic kidney cells and airway epithelial cells, a process catalyzed by the enzyme 'a disintegrin and metalloproteinase-17' (ADAM-17) $(42,43)$, but evidence for shedding ACE2 in vivo is limited. Other possibility is that ACE2 protein might derive via shedding from cells along the nephron by ADAM-1 7 activated by high blood glucose (44), which might lead to higher urinary ACE2 levels in subjects with CKD. These inverse relationships between urinary expression of ACE2 and renal function imply that urinary ACE2 expression might be a compensatory response of renal tissue to insults. Therefore, urinary ACE2 concentrations might clinically serve as a marker for microalbuminuria and its possible role as a marker for renal impairment needs to be explored further.

There were several limitations to our study. First, due to the cross-sectional nature of our study, we were not able to examine the temporal relationship between urinary ACE2 levels and the severity of glucose intolerance and related metabolic parameters. Longterm follow-up of larger groups is needed to establish the predictive relationship between urinary ACE2 concentrations and metabolic parameters and renal function. Additionally, our study subjects were not drug-naïve, and some subjects were on antihypertensives, glucose-lowering medications, or both, which could influence both urinary ACE2 concentrations and renal excretion of albumin. However, we did not observe significant differences in the urinary ACE2 levels for subjects undergoing ACE inhibitor or Ang II receptor blocker therapy $(P=0.14$, data not shown). Finally, we could not measure the serum levels of ACE2 with the use of the current ELISA assay in our study, likely due to the presence of very low levels of serum ACE2. Evidence for this interpretation was recently provided by Mizuiri et al. (24) in that they were able to detect serum ACE2 in western blot analysis only after 20-fold concentration in subjects whose expression patterns remained unchanged in response to CKD.

Nonetheless, our results suggested that urinary ACE2 levels are elevated in subjects with T2DM and are independently associated with a higher risk of microalbuminuria. We also detected significant relationships between urinary ACE2 concentrations and various metabolic and inflammatory markers. Urinary ACE2 concentrations will provide additional information about the role of kidney RAS and may be useful as a marker of glucose intolerance and renal dysfunction among subjects with glucose intolerance. Prospective studies are warranted to elucidate the role of urinary ACE2 measurement. 


\section{Supplementary data}

This is linked to the online version of the paper at http://dx.doi.org/10. 1530/EJE-12-0782.

\section{Declaration of interest}

J W Park, N Lee, and B-S Youn are employees of AdipoGen, Inc. The other authors have nothing to disclose.

\section{Funding}

This work was supported by AdipoGen, Inc.; Health Promotion Funds from the Korean Ministry for Health, Welfare, and Family Affairs; and the Welfare Bureau of the Seoul Metropolitan Government.

\section{References}

1 Leahy JL. Mary, Mary, quite contrary, how do your $\beta$-cells fail? Diabetes 200857 2563-2564. (doi:10.2337/db08-0869)

2 Stumvoll M, Goldstein BJ \& van Haeften TW. Type 2 diabetes: principles of pathogenesis and therapy. Lancet $2005 \mathbf{3 6 5}$ 1333-1346. (doi:10.1016/S0140-6736(05)61032-X)

3 Bindom SM \& Lazartigues E. The sweeter side of ACE2: physiological evidence for a role in diabetes. Molecular and Cellular Endocrinology 2009302 193-202. (doi:10.1016/j.mce.2008.09. 020)

4 Abuissa H, Jones PG, Marso SP \& O'Keefe JH Jr. Angiotensinconverting enzyme inhibitors or angiotensin receptor blockers for prevention of type 2 diabetes: a meta-analysis of randomized clinical trials. Journal of the American College of Cardiology 200546 821-826. (doi:10.1016/j.jacc.2005.05.051)

5 McMurray JJ, Holman RR, Haffner SM, Bethel MA, Holzhauer B, Hua TA, Belenkov Y, Boolell M, Buse JB, Buckley BM et al. Effect of valsartan on the incidence of diabetes and cardiovascular events. New England Journal of Medicine 2010362 1477-1490. (doi:10. 1056/NEJMcp0909392)

6 Donoghue M, Hsieh F, Baronas E, Godbout K, Gosselin M, Stagliano N, Donovan M, Woolf B, Robison K, Jeyaseelan R et al. A novel angiotensin-converting enzyme-related carboxypeptidase (ACE2) converts angiotensin I to angiotensin 1-9. Circulation Research 200087 E1-E9. (doi:10.1161/01.RES.87.5.e1)

7 Crackower MA, Sarao R, Oudit GY, Yagil C, Kozieradzki I, Scanga SE, Oliveira-dos-Santos AJ, da Costa J, Zhang L, Pei Y et al. Angiotensin-converting enzyme 2 is an essential regulator of heart function. Nature $2002 \mathbf{4 1 7} 822-828$. (doi:10.1038/ nature00786)

8 Turner AJ \& Hooper NM. The angiotensin-converting enzyme gene family: genomics and pharmacology. Trends in Pharmacological Sciences 200223 177-183. (doi:10.1016/S0165-6147(00) 01994-5)

9 Kalea AZ \& Batlle D. Apelin and ACE2 in cardiovascular disease. Current Opinion in Investigational Drugs 201011 273-282.

10 Wysocki J, Ye M, Rodriguez E, Gonzalez-Pacheco FR, Barrios C, Evora K, Schuster M, Loibner H, Brosnihan KB, Ferrario CM et al. Targeting the degradation of angiotensin II with recombinant angiotensin-converting enzyme 2: prevention of angiotensin II-dependent hypertension. Hypertension $2010 \quad 55$ 90-98. (doi:10.1161/HYPERTENSIONAHA.109.138420)

11 Niu MJ, Yang JK, Lin SS, Ji XJ \& Guo LM. Loss of angiotensinconverting enzyme 2 leads to impaired glucose homeostasis in mice. Endocrine 200834 56-61. (doi:10.1007/s12020-0089110-x)

12 Mykkanen L, Zaccaro DJ, O'Leary DH, Howard G, Robbins DC \& Haffner SM. Microalbuminuria and carotid artery intima-media thickness in nondiabetic and NIDDM subjects. The Insulin Resistance Atherosclerosis Study (IRAS). Stroke $1997 \mathbf{2 8}$ 1710-1716. (doi:10.1161/01.STR.28.9.1710)
13 Stehouwer CD, Gall MA, Twisk JW, Knudsen E, Emeis JJ \& Parving HH. Increased urinary albumin excretion, endothelial dysfunction, and chronic low-grade inflammation in type 2 diabetes: progressive, interrelated, and independently associated with risk of death. Diabetes 200251 1157-1165. (doi:10.2337/ diabetes.51.4.1157)

14 Parvanova AI, Trevisan R, Iliev IP, Dimitrov BD, Vedovato M, Tiengo A, Remuzzi G \& Ruggenenti P. Insulin resistance and microalbuminuria: a cross-sectional, case-control study of 158 patients with type 2 diabetes and different degrees of urinary albumin excretion. Diabetes 200655 1456-1462. (doi:10.2337/ $\mathrm{db} 05-1484)$

15 Ruster C \& Wolf G. Renin-angiotensin-aldosterone system and progression of renal disease. Journal of the American Society of Nephrology $2006 \quad 17$ 2985-2991. (doi:10.1681/ASN. 2006040356)

16 Williams ME. Diabetic nephropathy: the proteinuria hypothesis. American Journal of Nephrology 200525 77-94. (doi:10.1159/ 000084286)

17 Ye M, Wysocki J, William J, Soler MJ, Cokic I \& Batlle D. Glomerular localization and expression of angiotensin-converting enzyme 2 and angiotensin-converting enzyme: implications for albuminuria in diabetes. Journal of the American Society of Nephrology 200617 3067-3075. (doi:10.1681/ASN.2006050423)

18 Mizuiri S, Hemmi H, Arita M, Ohashi Y, Tanaka Y, Miyagi M, Sakai K, Ishikawa Y, Shibuya K, Hase $\mathrm{H}$ et al. Expression of ACE and ACE2 in individuals with diabetic kidney disease and healthy controls. American Journal of Kidney Diseases 200851 613-623. (doi:10.1053/j.ajkd.2007.11.022)

19 Reich HN, Oudit GY, Penninger JM, Scholey JW \& Herzenberg AM. Decreased glomerular and tubular expression of ACE2 in patients with type 2 diabetes and kidney disease. Kidney International 2008 74 1610-1616. (doi:10.1038/ki.2008.497)

20 Wysocki J, Ye M, Soler MJ, Gurley SB, Xiao HD, Bernstein KE, Coffman TM, Chen S \& Batlle D. ACE and ACE2 activity in diabetic mice. Diabetes 200655 2132-2139. (doi:10.2337/db06-0033)

21 Ye M, Wysocki J, Naaz P, Salabat MR, LaPointe MS \& Batlle D. Increased ACE 2 and decreased ACE protein in renal tubules from diabetic mice: a renoprotective combination? Hypertension 2004 43 1120-1125. (doi:10.1161/01.HYP.0000126192.27644.76)

22 Wang G, Lai FM, Lai KB, Chow KM, Kwan CH, Li KT \& Szeto CC. Urinary mRNA expression of ACE and ACE2 in human type 2 diabetic nephropathy. Diabetologia 200851 1062-1067. (doi:10. 1007/s00125-008-0988-x)

23 Warner FJ, Lew RA, Smith AI, Lambert DW, Hooper NM \& Turner AJ. Angiotensin-converting enzyme 2 (ACE2), but not ACE, is preferentially localized to the apical surface of polarized kidney cells. Journal of Biological Chemistry $2005 \mathbf{2 8 0}$ 39353-39362. (doi:10.1074/jbc.M508914200)

24 Mizuiri S, Aoki T, Hemmi H, Arita M, Sakai K \& Aikawa A. Urinary angiotensin-converting enzyme 2 in patients with CKD. Nephrology $2011 \quad 16$ 567-572. (doi:10.1111/j.1440-1797. 2011.01467.x)

25 Batlle D, Jose Soler M \& Ye M. ACE2 and diabetes: ACE of ACEs? Diabetes 201059 2994-2996. (doi:10.2337/db10-1205)

26 Won JC, Park CY, Park HS, Kim JH, Choi ES, Rhee EJ, Lee WY, Oh KW, Kim SW \& Park SW. 1,5-Anhydroglucitol reflects postprandial hyperglycemia and a decreased insulinogenic index, even in subjects with prediabetes and well-controlled type 2 diabetes. Diabetes Research and Clinical Practice 200984 51-57. (doi:10.1016/j.diabres.2009.01.002)

27 American Diabetes Association. Diagnosis and classification of diabetes mellitus. Diabetes Care 200528 (Suppl 1) S37-S42. (doi:10.2337/diacare.28.suppl_1.S37)

28 Curb JD, Ford C, Hawkins CM, Smith EO, Zimbaldi N, Carter B \& Cooper C. A coordinating center in a clinical trial: the Hypertension Detection and Followup Program. Controlled Clinical Trials 19834 171-186. (doi:10.1016/0197-2456(83)90001-6)

29 Matthews DR, Hosker JP, Rudenski AS, Naylor BA, Treacher DF \& Turner RC. Homeostasis model assessment: insulin resistance and 
$\beta$-cell function from fasting plasma glucose and insulin concentrations in man. Diabetologia $1985 \mathbf{2 8} 412-419$. (doi:10.1007/ BF00280883)

$30 \mathrm{~K} / \mathrm{DOQI}$ clinical practice guidelines for chronic kidney disease: evaluation, classification, and stratification. American Journal of Kidney Diseases 200239 S1-S266. (doi:10.1016/S02726386(02)70081-4)

31 Carlsson PO, Berne C \& Jansson L. Angiotensin II and the endocrine pancreas: effects on islet blood flow and insulin secretion in rats. Diabetologia 199841 127-133. (doi:10.1007/ s001250050880)

32 Cooper ME, Tikellis C \& Thomas MC. Preventing diabetes in patients with hypertension: one more reason to block the reninangiotensin system. Journal of Hypertension. Supplement $2006 \mathbf{2 4}$ S57-S63. (doi:10.1097/01.hjh.0000220408.91987.eb)

33 Takahashi Y, Haga S, Ishizaka Y \& Mimori A. Autoantibodies to angiotensin-converting enzyme 2 in patients with connective tissue diseases. Arthritis Research and Therapy 201012 R85. (doi:10.1186/ar3012)

34 Dilauro M, Zimpelmann J, Robertson SJ, Genest D \& Burns KD. Effect of ACE2 and angiotensin-(1-7) in a mouse model of early chronic kidney disease. American Journal of Physiology. Renal Physiology 2010298 F1523-F1532. (doi:10.1152/ajprenal. $00426.2009)$

35 Xiao F, Hiremath S, Knoll G, Zimpelmann J, Srivaratharajah K, Jadhav D, Fergusson D, Kennedy CR \& Burns KD. Increased urinary angiotensin-converting enzyme 2 in renal transplant patients with diabetes. PLoS ONE 20127 e37649. (doi:10.1371/ journal.pone.0037649)

36 Sampaio WO, Souza dos Santos RA, Faria-Silva R, da Mata Machado LT, Schiffrin EL \& Touyz RM. Angiotensin-(1-7) through receptor Mas mediates endothelial nitric oxide synthase activation via Akt-dependent pathways. Hypertension 200749 185-192. (doi:10.1161/01.HYP.0000251865.35728.2f)

37 Santos SH, Fernandes LR, Mario EG, Ferreira AV, Porto LC, Alvarez-Leite JI, Botion LM, Bader M, Alenina N \& Santos RA. Mas deficiency in FVB/N mice produces marked changes in lipid and glycemic metabolism. Diabetes 200857 340-347. (doi:10.2337/ db07-0953)
38 Suzuki Y, Ruiz-Ortega M, Lorenzo O, Ruperez M, Esteban V \& Egido J. Inflammation and angiotensin II. International Journal of Biochemistry and Cell Biology 200335 881-900. (doi:10.1016/ S1357-2725(02)00271-6)

39 Huentelman MJ, Grobe JL, Vazquez J, Stewart JM, Mecca AP, Katovich MJ, Ferrario CM \& Raizada MK. Protection from angiotensin II-induced cardiac hypertrophy and fibrosis by systemic lentiviral delivery of ACE2 in rats. Experimental Physiology 200590 783-790. (doi:10.1113/expphysiol.2005.031096)

40 Donath MY, Storling J, Maedler K \& Mandrup-Poulsen T. Inflammatory mediators and islet $\beta$-cell failure: a link between type 1 and type 2 diabetes. Journal of Molecular Medicine $2003 \mathbf{8 1}$ 455-470. (doi:10.1007/s00109-003-0450-y)

41 Johnson JD, Ahmed NT, Luciani DS, Han Z, Tran H, Fujita J, Misler S, Edlund $\mathrm{H}$ \& Polonsky KS. Increased islet apoptosis in Pdx $1+/-$ mice. Journal of Clinical Investigation 2003111 1147-1160. (doi:10.1172/JCI200316537)

42 Iwata M, Silva Enciso JE \& Greenberg BH. Selective and specific regulation of ectodomain shedding of angiotensin-converting enzyme 2 by tumor necrosis factor $\alpha$-converting enzyme. American Journal of Physiology. Cell Physiology 2009297 C1318-C1329. (doi:10.1152/ajpcell.00036.2009)

43 Jia HP, Look DC, Tan P, Shi L, Hickey M, Gakhar L, Chappell MC, Wohlford-Lenane C \& McCray PB Jr. Ectodomain shedding of angiotensin converting enzyme 2 in human airway epithelia. American Journal of Physiology. Lung Cellular and Molecular Physiology 2009 297 L84-L96. (doi:10.1152/ajplung.00071.2009)

44 Reddy AB, Ramana KV, Srivastava S, Bhatnagar A \& Srivastava SK. Aldose reductase regulates high glucose-induced ectodomain shedding of tumor necrosis factor (TNF)- $\alpha$ via protein kinase C-delta and TNF- $\alpha$ converting enzyme in vascular smooth muscle cells. Endocrinology 2009150 63-74. (doi:10.1210/en.2008-0677)

Received 2 May 2012

Revised version received 29 October 2012

Accepted 8 November 2012 